\title{
APPLICATION OF EXPLICIT-IMPLICIT CO-SIMULATION TECHNIQES INTO THE ROLL PASS DESIGN OF CHANNELS WITH LARGE DEFORMATIONS
}

\author{
${ }^{1}$ Michał DZIEDZIC, ${ }^{1}$ Stanisław TURCZYN \\ ${ }^{1}$ AGH University of Science and Technology, Cracow, Poland, EU, \\ dziedzic@agh.edu.pl, turczyn@metal.agh.edu.pl
}

https://doi.org/10.37904/metal.2020.3479

\begin{abstract}
The practical aim of the following study was to develop a new roll pass design (RPD) of the channels (UPN) and introduce it into industrial rolling. The necessity of usage of a charge stock with a greater cross section has caused necessity of an application of the new rolling schedule characterized by large deformations. The investigations are based on an explicit-implicit co-simulation techniques applied in the ABAQUS commercial code. A complete production line containing all passes for forming the section including break-down, intermediate and finishing sequences are modelled. The data of exit section from subsequent pass is imported as the entering material for the next pass. The series of the plastometric tests were performed to obtain characteristic data of the rolled steel, which were required for the subsequent computer calculations. The metal flow in the roll grooves in each stand, separation force and roll torque in each pass are also calculated. It can be concluded that the explicit-implicit co-simulation techniques used in the analysis are an efficient and accurate enough application for the roll pass design of the steel sections.
\end{abstract}

Keywords: Roll pass design, finite element analysis, channels rolling, material tests

\section{INTRODUCTION}

The quality and productivity of hot rolled steel section strongly depends on the rolling parameters such as strain, strain rate, temperature, groove design and rolling sequence. The knowledge of the process parameters is important for the creation and optimization of the roll pass design, including the pass schedule and the properties of the final products [1-3]. Roll pass design for the rolling of steel sections remains an expensive experience based on trial-and-error process [9]. Consequently, analysis and optimization of roll-pass design remain important objectives [8]. Computer simulations are another common way to predict the rolling parameters [5]. Simulation models can be built in the earlier phase of engineering, allowing the optimization and evaluation of different designs [10]. Many researchers have been working in the field of grooves design using implicit or explicit techniques [4,7], but there is no complete analytical design for the whole chain of grooves for section rolling. The reason is that the dependence of the process from different variables interfering the results of designing the shape grooves used in the rolling process.

Recent advances in the computer technology have enabled researchers to build more complicated and comprehensive numerical models to study the roll pass design problems [6]. These models often provide relatively quick results compared to experimental methods. Improvements in algorithm and formulation of the loads and boundary conditions have enabled researchers to obtain a more accurate representation of the phenomenon of hot rolling of the sections in the complex grooves [5-6]. Implicit or explicit solvers, each of them has specific advantages and disadvantages. However, from many years there is possibility of combining these two methods into a hybrid analysis, called co-simulation [11].

In the paper, the implicit - explicit (co-simulation) finite element software ABAQUS was used to simulate hot rolling of channel using 15 passes and according to the process in Celsa Huta Ostrowiec. These passes 
include both simple initial passes as well as complicated finishing passes. Co-simulation technique allowed combining heterogeneous solvers and were less time consuming in comparison to the solution when different load and model cases required an additional amount of time for the comunications between two different solvers [11]. The heat transfer is considered in each stand. The section geometry of the calculated and experimental results have been compared. Due to the good agreement between the numerical and the experimental results, the numerical simulation has been applied to predict the values of different rolling parameters occurred when new roll pass design was used.

\section{EXPERIMENTAL SETUP}

The finite element simulation modelling was performed with the aid of commercial code ABAQUS ver. 6.20. Co-simulation static implicit-dynamic explicit method was adopted for all calculations. As Abaqus code has both implicit and explicit solvers, with the possibility to transfer the information between them by the IMPORT capability, applied in both directions, from implicit to explicit and vice-versa, it has been chosen, in the present study, as reference code for non-linear transient analysis of the hot rolling process of the channels, Figure 1. A common region was defined for both implicit and explicit models, referred to as the interface regions. The interface regions are node sets and surfaces when coupling Abaqus-Standard to Abaqus-Explicit. The implicit region provides the boundary condition and loadings to the explicit region through these nodes. Three-dimensional, deformable and linear hexahedral (brick) element is used to model the stock. The rolls are non-deformable rigid bodies, all horizontal rolls have a constant circumferential speed shown in the Table 1. The surface between roll and stock is defined as a general contact. The Coulomb friction model is considered as the contact algorithm. The thermal transfer coefficient for the stock is very low and reaches values that range between $15 \div 50 \mathrm{~W} /\left(\mathrm{m}^{2} \cdot \mathrm{K}\right)$. The thermal flow is magnified with water cooling and the thermal transfer coefficient reaches values ranging between $500 \div 4000 \mathrm{~W} /\left(\mathrm{m}^{2} \cdot \mathrm{K}\right)$. The thermal transfer coefficient in the contact area between rolls and stock is very high and attains values of between $6000 \div 10000 \mathrm{~W} /\left(\mathrm{m}^{2} \cdot \mathrm{K}\right)$. Apart from the thermal flow due to convection, rolling stock heat is as well lost due to radiation.

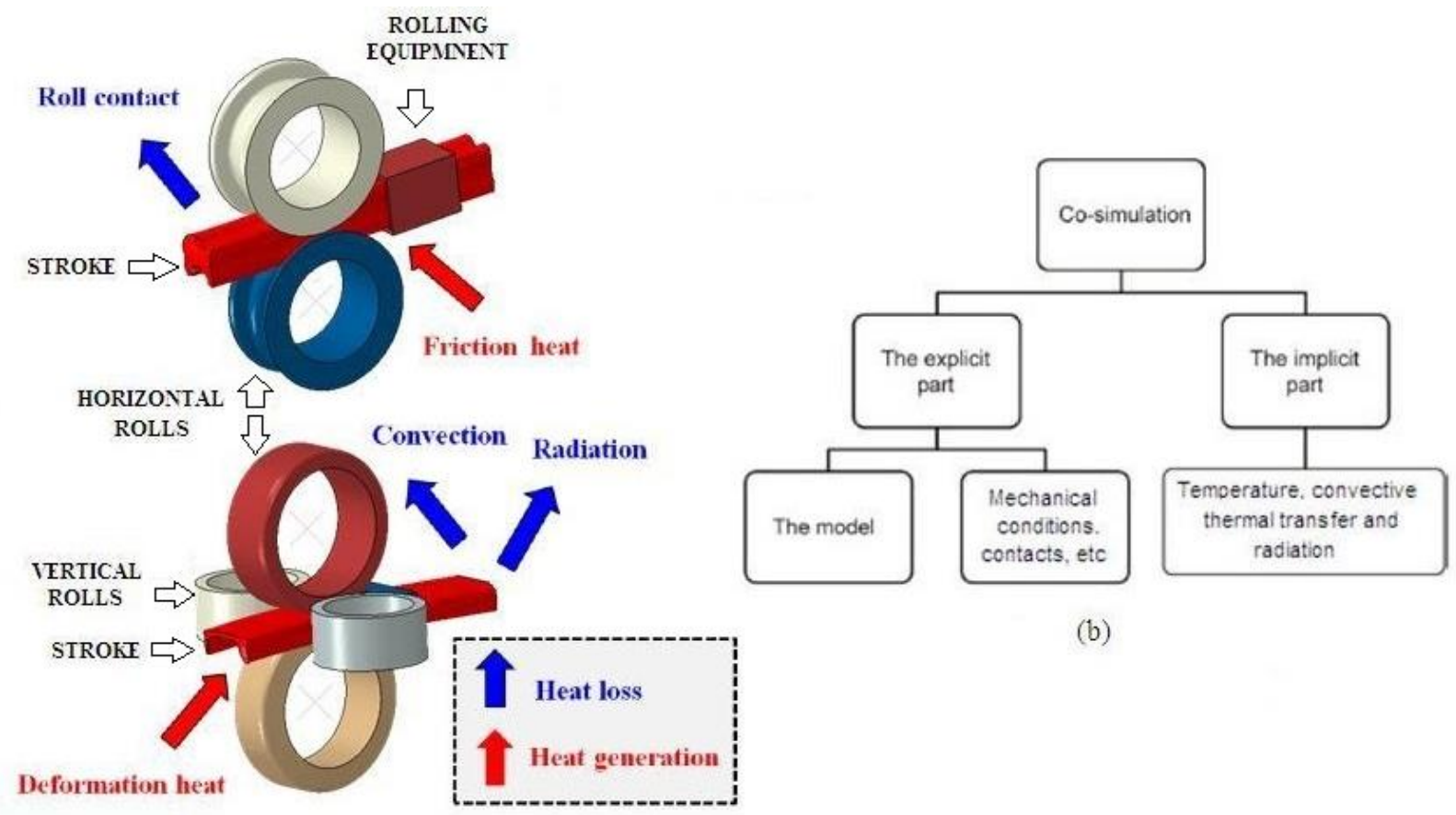

(a)

Figure 1 Explicit and implicit co-simulation (a) The complete model; (b) division of the co-simulation 
Because of large deformations happening during the channels rolling in the shape grooves, ALE adaptive meshing provides mesh distortion control. The rolling process of the analysed channel includes 15 passes. The temperature of entering stock into pass 1 is considered to be $1258^{\circ} \mathrm{C}$. The rolls are constrained to rotate only in one direction and the magnitude of rotation is based on the applied rolling technology. These data are used as a boundary condition in the finite element model. The velocity of the stock at the entry to the stands are used as initial conditions in the model, Table 1.

Table 1 Applied process parameters in each stand

\begin{tabular}{|c|c|c|c|c|c|c|c|c|c|c|c|c|c|c|c|}
\hline $\begin{array}{c}\text { Linear } \\
\text { velocity in } \\
\text { stand } \\
\text { (m/s) }\end{array}$ & $\mathbf{1}$ & $\mathbf{2}$ & $\mathbf{3}$ & $\mathbf{4}$ & $\mathbf{5}$ & $\mathbf{6}$ & $\mathbf{7}$ & $\mathbf{8}$ & $\mathbf{9}$ & $\mathbf{1 0}$ & $\mathbf{1 1}$ & $\mathbf{1 2}$ & $\mathbf{1 3}$ & $\mathbf{1 4}$ & $\mathbf{1 5}$ \\
\hline $\begin{array}{c}\text { UPN } \\
\text { channel }\end{array}$ & 0.5 & 0.7 & 0.8 & 0.9 & 1.0 & 1.13 & 1.22 & 1.31 & 1.6 & 1.71 & 1.98 & 2.33 & 2.47 & 2.86 & 3.03 \\
\hline rolls & 0.7 & 0.8 & 0.9 & 1.0 & 1.13 & 1.22 & 1.31 & 1.6 & 1.71 & 1.98 & 2.33 & 2.47 & 2.86 & 3.03 & 3.5 \\
\hline
\end{tabular}

Figure 1a shows the geometry and discretization of channels (UPN 300) and rolls. Flow stresses for steel obtained from the tests for the strain rate up to $0.2 \mathrm{~s}^{-1}$ and different temperatures are presented in the Figure 2. From the flow stress shown in the Figure 2, a distinct effect of strain and strain rate on the value of $\sigma_{p}$ can be observed.

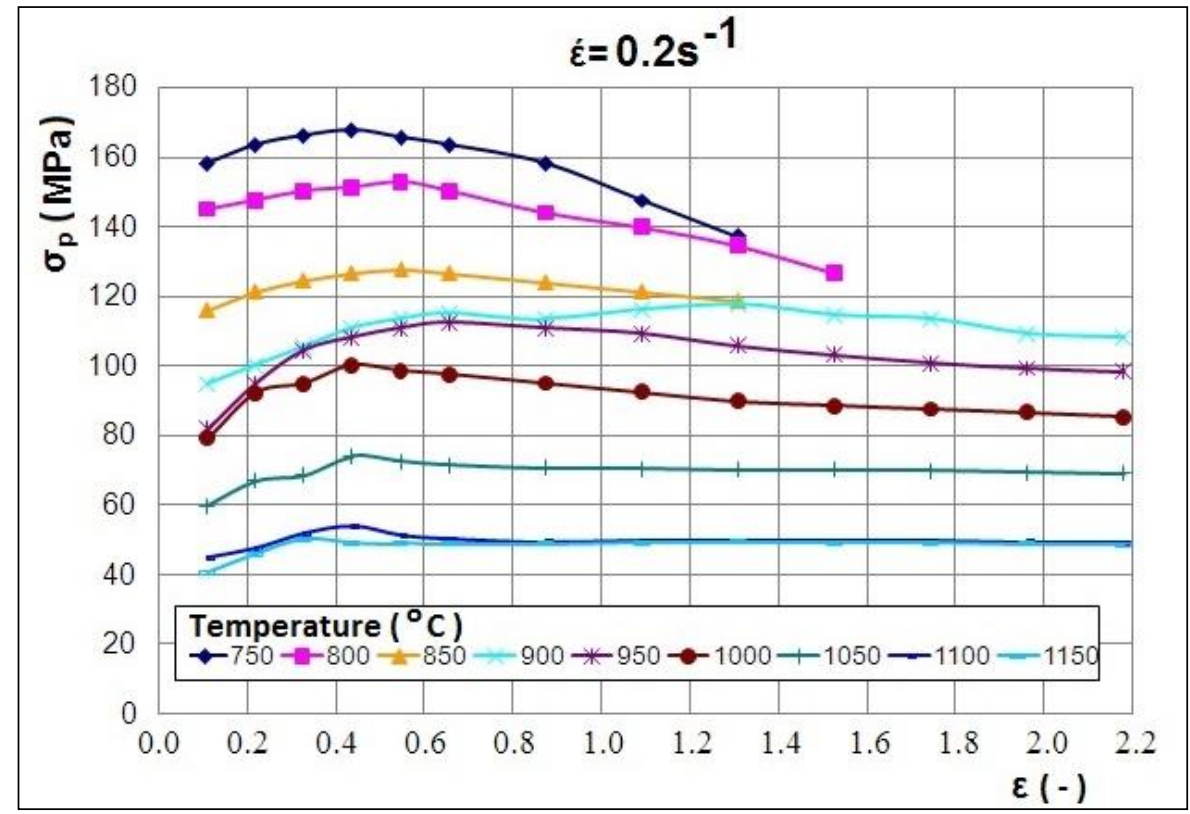

Figure 2 Flow stress of rolled steel (S355 grade) as deformed at strain rate rate $0.2 \mathrm{~s}^{-1}$

The plastic flow curves of the stock were calculated based on the torsion test and grouped in sets of strain, strain rate and temperature, in ascending order. The following thermo-physical variables, i.e. the differential, linear thermal expansion coefficient, the thermal conductivity value, and true specific thermal capacity are integrated in the form of value pairs as a function of temperature in Abaqus solver.

\section{RESULTS OF NUMERICAL SIMULATION}

In each roll pass design of sections there are some critical parameters that are important to evaluate the validity of the groove design. Exit cross section in each stand, separating force between rolls, torque and power 
consumption in each stage are the samples of main parameters for a roll pass design. With implicit-explicit cosimulation analysis all of the above parameters can be calculated in each pass. Groove filling and the entire process of channels rolling is very sensitive to small variations of rolling parameters. However, the principal factor is to ensure right metal flow in all part of the groves. The example grooves filling in the knife grooves during hot rolling of the channels are presented in Figure 3 and Figure 4. As can be seen in these figures, right filling of the newly designed grooves by the metal is observed.
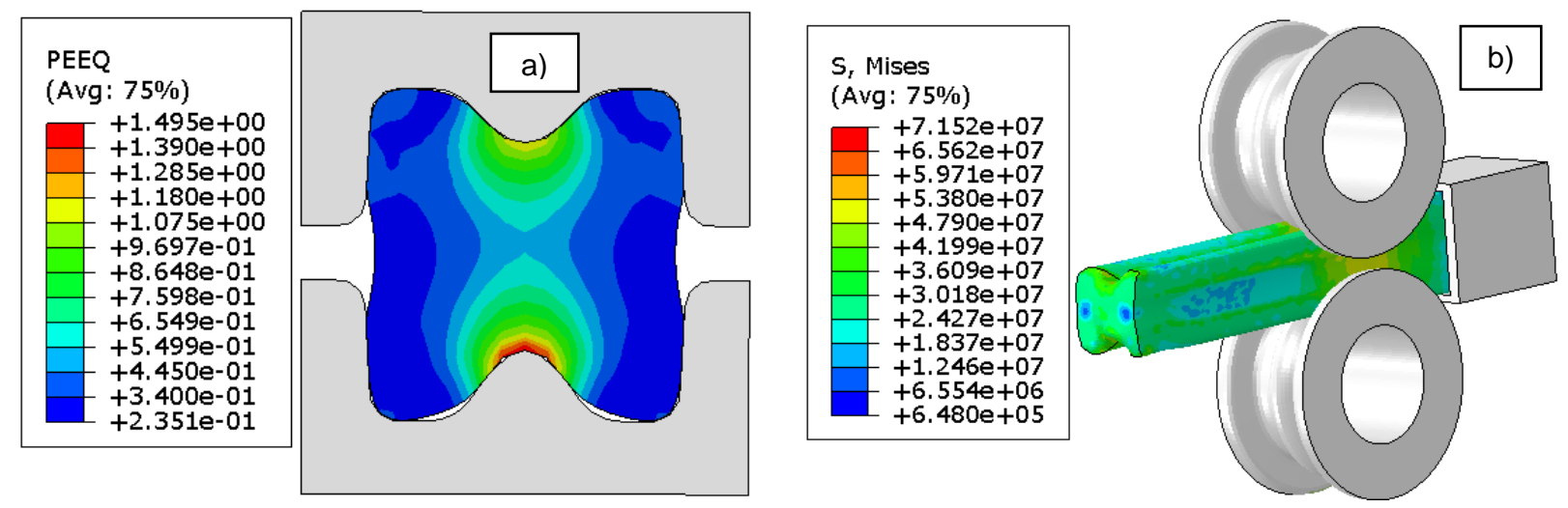

Figure 3 Shape of the stock during rolling of channels in the groove No. 2: (a) distribution of equivalent plastic strain; (b) strip shape at the exit from the groove
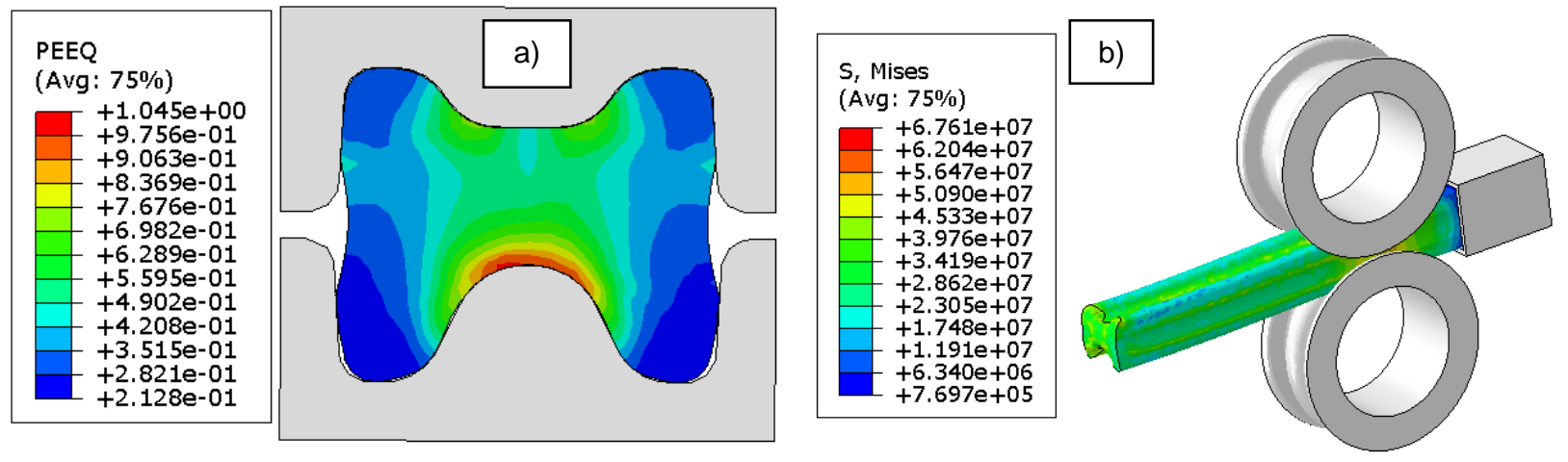

Figure 4 Shape of the stock during rolling of channels in the groove No. 3: (a) distribution of equivalent plastic strain, (b) strip shape at the exit from the groove

For the edging deformations four different grooves in the universal stands are used. Although this solution has a disadvantage that the stands must be shifted sideways during the rolling process, which require extra time, it was still chosen because it enables the flange height and the geometry of the outside transition radius between the web and the flange to be optimally controlled. Second pass of pre-edging are shown in the Figure 5. The distribution of maximal principal stresses causes that rolling stock leaves the gap irregularly. The top part of the section is clearly more elongated than the bottom one, with the consequence that the material moves away downwards, Figure 6a. Such situation is dangerous for roll accessories and was changed during roll pass design. Balancing of the groove neutral line with the rolling line causes that the material moves away straight, Figure $6 \mathrm{~b}$.

Figure 7a shows the value of roll separating forces. These forces determine the diameter of work roll because the level of roll separating forces cause stresses in the working rolls. As illustrated in Figure 7a, the roll separating force in stand 12 is increased to other stands because the restriction factor in this stand is higher than other passes. 


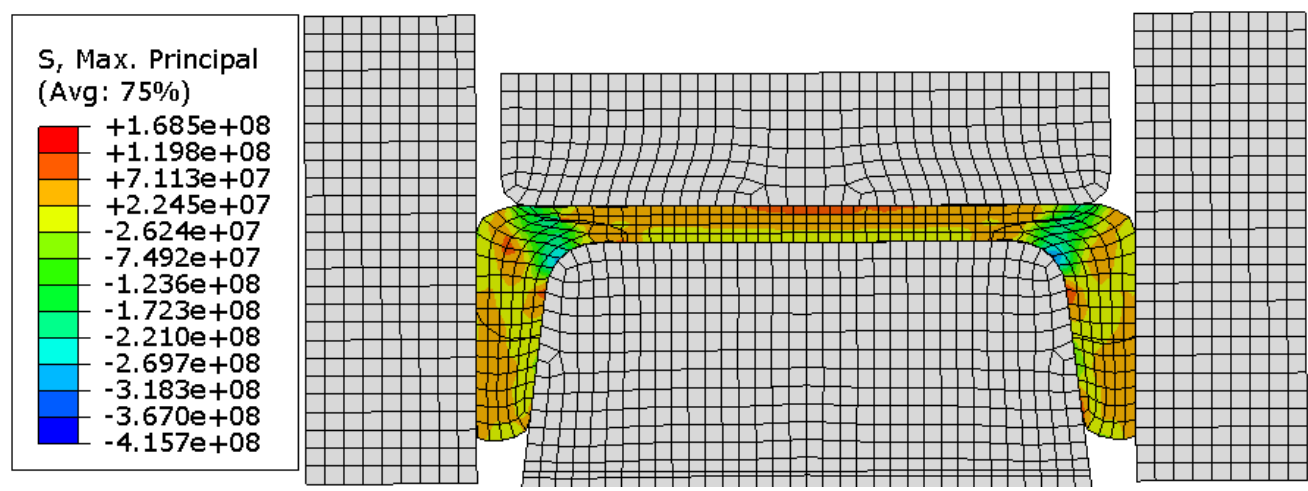

Figure 5 Shape of the stock and distribution of maximal principal stresses during rolling of channels in the groove No. 10
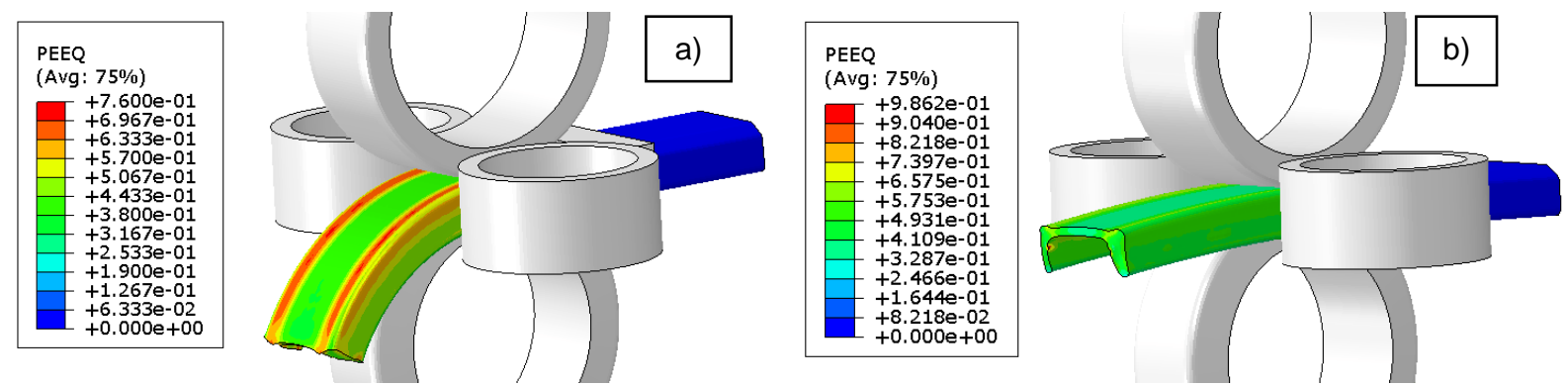

Figure 6 Strip shape at the exit from of the groove: a) wrong location of the rolling line, b) balance of the groove neutral line with the rolling line
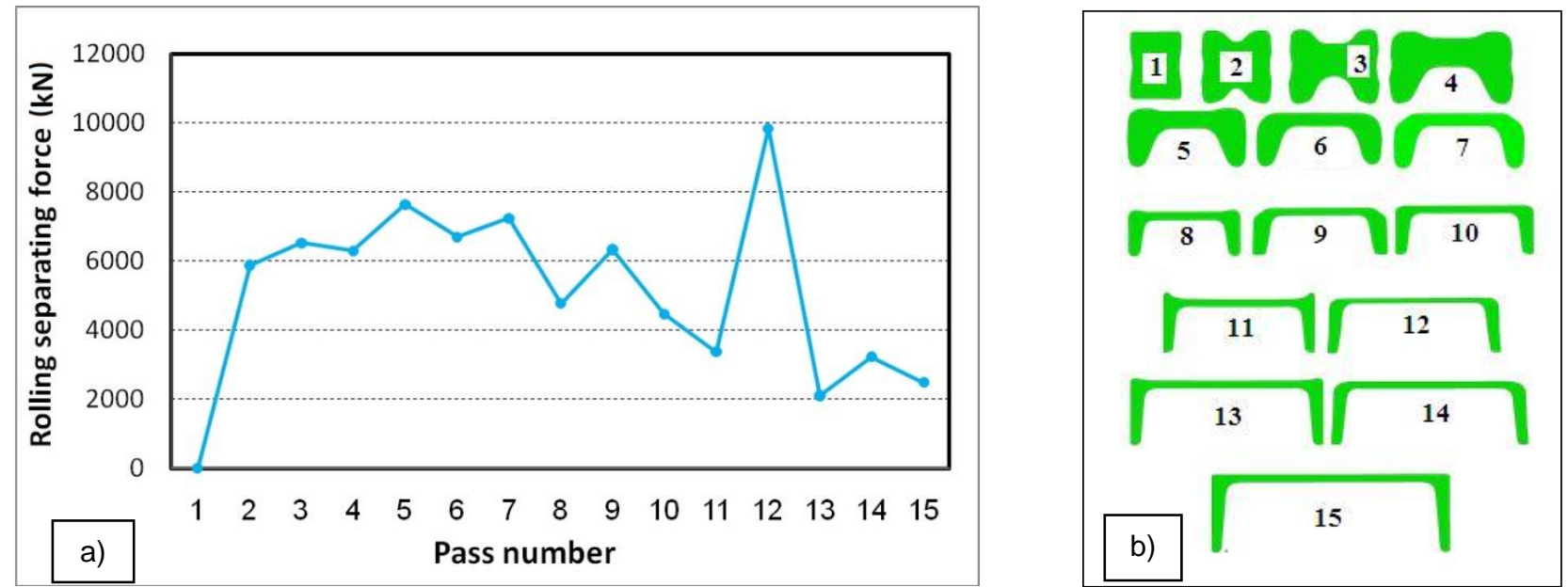

Figure 7 Calculated roll separating force in each pass (a) and cross section of UPN 300 at the exit plan of each passes (b)

The most important results of each designed roll groove are geometrical dimensions at exit cross section in each pass. The exit cross section in each pass is affected by spread and it is necessary to control the spread in each groove. Moreover, the goal of the roll pass design is to meet the standard cross section at the end of the process. In this manner, after each pass, the cross section of product was exported and used as entering geometry to next pass. Figure $\mathbf{7 b}$ shows all cross sections of the rolled channel in the 15 passes. It is worthily to mention that the final cross section from last stand was exactly equal to the channel UPN 300 which is rolled in the real process line in Celsa Huta Ostrowiec. 


\section{CONCLUSIONS}

In the present study, hot rolling of steel channel is investigated by utilizing the three dimensional, explicitimplicit co-simulation FEM techniques. The most important part of this research is the simulation of a whole production line from the initial billet to the final product, which include complicated initial and final passes in two-high and four-high stands. The important parameters in the roll pass design like dimensions of the grooves, the roll separating forces in each stand are computed. Then the metal flow inside the grooves has been analysed. The focus was laid as well on the bending occurrence when the channels leaving the roll gap. It was determined that the rolled sections have a strong bending against the roller table. These deficiencies were solved by modifying grooves geometry, so that a safe rolling process can be guaranteed within the requested tolerances. It was proved under operating conditions. To verify the accuracy of finite element simulations presented in this paper, obtained results have been compared with real information from the production line in Celsa Huta Ostrowiec. A good agreement between the results with the experimental values makes this method very useful to the roll pass designers, especially to design complicated roll passes. Explicit-implicit cosimulation is a reliable technique where all rolling parameters can be computed at every stage making it a very useful tool in the roll pass design of sections with less time and expenses in comparison to the empirical methods.

\section{ACKNOWLEDGEMENTS}

This research has been founded by European Union in the area of POIR project (Granted No. 01.02.00-00-0179/16-00). We also thank the ACC Cyfronet AGH for the computational support of this investigation performed in part by PLGrid Infrastructure.

\section{REFERENCES}

[1] WOSIEK, E., NOWAKOWSKI, A. Roll Pass Design. AGH Edition. Kraków. 1981.

[2] PARK, J. J., OH, S. I. Application of Three Dimensional Finite Element Analyses to Shape Rolling Processes. ASME Journal of Engineering for Industry. 1990, vol. 112, pp. 36-46.

[3] HARRER, O., BUCHMAYR, B., RIEDL, A. Simulation des Walzens von Rippenplatten UIC60-0. 2010. MEFORM 2010 Tagungsband, pp. 226-237.

[4] LEHNERT, W., LEMKE, J., SCHMIDT, B. The experimental and mathematical simulation of rolling in grooves, Der Kalibreur. 1998, vol 59, pp. 15-24.

[5] KAWALLA, R. Development of simulation software for the analysis of multi stage hot rolling of strips and wire rod. METABK. 2010, vol. 49, pp.175-179.

[6] SCHMITZ, G. J., PRAHL, U. Integrative computational materials engineering. Applications of a modular simulation platform, Wiley-VCH Verlag GmbH \& Co. KGaA, 2012, pp. 148.

[7] TAKASHIMA, Y. T-bar Universal Rolling and Ist Deformation Properties. ISIJ International. 2012, vol. 52, pp. 1328-1334.

[8] DZIEDZIC, M., TURCZYN, S. Assessment of metal flow during rolling of sheet piles. Der Kalibreur. 2016, vol. 77, pp. 56-63.

[9] YERSHOW, S., MEL'NIK, S., KRAVCHENKO, E. A review and technology analysis of rolling channel sections in rolling mills in the CIS. International Journal of Engineering and Technologies. 2016, vol. 6, pp. 8-19.

[10] DZIEDZIC, M., TURCZYN, S, KUŹMIŃSKI, Z. Investigation of metal flow inside shape grooves during rolling of channels with large deformations. Computer methods in material science. 2019, vol. 19, pp. 107-112.

[11] HONGZHOU, H., ZHIHUA, Z. Explicit - Implicit Co-Simulation Techniques for Dynamic Responses of a Passenger Car on Arbitrary Road Surfaces. Engineering. 2019, vol 5, no. 6, pp. 1171-1178. 